\title{
Induction of physiological acrosome reactions in caput epididymal spermatozoa of mice
}

\author{
B. E. Biegler, D. J. Aarons, B. C. George and G. R. Poirier*
}

Department of Biology, University of Alabama at Birmingham, Birmingham, AL 35294-1170,

USA

\begin{abstract}
Mouse caput spermatozoa are considered immature and thus unable to fertilize oocytes. In this study, we determined whether washing mouse caput spermatozoa increased their ability to acrosome react in response to a physiological stimulus. The results obtained showed that mouse caput spermatozoa incubated in Earles' modified medium containing calcium chloride and supplemented with BSA and pyruvate for $1 \mathrm{~h}$ at $37^{\circ} \mathrm{C}$ and then washed acrosome reacted in response to both solubilized zonae and immunoaggregation of a zona binding site. In addition, the material removed from caput spermatozoa by washing blocked induced acrosome reactions of cauda spermatozoa. The data indicate that mouse caput epididymal spermatozoa, if incubated and washed, can undergo physiological acrosome reactions.
\end{abstract}

\section{Introduction}

Spermatozoa leaving the testes are immature. During epididymal transit, they undergo a number of structural, biochemical and functional changes resulting in their ability to fertilize. Collectively, these changes constitute epididymal maturation (Orgebin-Crist, 1987; Yanagimachi, 1988). Maturation includes, among other events, the incorporation, release or modification of components of the plasma membrane. The plasma membrane is important in the study of maturation because it is directly involved in a number of significant prefertilization events: capacitation, zona binding, the acrosome reaction and sperm-egg fusion. The plasma membrane is the site of the most prominent changes occurring during epididymal maturation (Yanagimachi, 1981).

In mice, caput spermatozoa are immotile and when incubated under capacitating conditions cannot bind to zonae (Saling, 1982). Cauda spermatozoa, however, can bind to zonae even when their motility is compromised. It was considered that during epididymal maturation the ability to bind was due to an unmasking or transformation of zonae binding components already present (Saling, 1982) or the addition of zonae binding components from epididymal secretions (Peterson et al., 1986). If caput spermatozoa are incubated under capacitating conditions and then washed, their ability to bind zonae is greatly enhanced (McLaughlin and Shur, 1987). During fertilization, spermatozoa bind to the zona and undergo a zona-induced acrosome reaction which facilitates zona penetration. Although caput spermatozoa can undergo ionophore-induced acrosome reactions, they are unresponsive to zona stimulation (Lakoski et al., 1988). These spermatozoa were incubated under capacitating conditions, but not washed. Since washing increases binding ability, we

\footnotetext{
${ }^{*}$ Correspondence.
}

Received 13 April 1993. determined whether the washing would also increase the ability of spermatozoa to undergo zona-induced acrosome reactions.

Mouse caput epididymal spermatozoa, when incubated under capacitating conditions and washed, were shown to acrosome react to a zona stimulus as well as by immunoaggregation of a zona-binding site.

\section{Materials and Methods}

\section{Animals}

ICR mice, 6-12 weeks of age, were used throughout the study. These animals were subjected to controlled lighting (16 h light: $8 \mathrm{~h}$ dark) and constant temperature $\left(22^{\circ} \pm 2^{\circ} \mathrm{C}\right)$ and had free access to food and water.

\section{Isolation, capacitation and washing of spermatozoa}

The medium (M199-M) used for the isolation of spermatozoa and capacitations was Earles' modified medium 199 (Sigma, St Louis, MO) containing $1.8 \mathrm{mmol} \mathrm{CaCl}_{2} \mathrm{l}^{-1}$ and supplemented with $2 \mathrm{mg} \mathrm{BSA} \mathrm{ml} \mathrm{ml}^{-1}$ (Sigma) and $30 \mu \mathrm{g}$ pyruvate $\mathrm{ml}^{-1}$ (Sigma). The epididymis was divided into segments as proposed by Pavlok (1974). The caput, as used here, consisted of the proximal caput and the proximal portion of the distal caput. The cauda segment consisted of the proximal, middle and distal caudal regions. Caput and cauda regions were removed and placed in separate dishes in M199-M. Spermatozoa were removed from the cauda region by exerting pressure on the tissue, forcing concentrated spermatozoa into the medium. Spermatozoa were removed from the caput region by the technique reported by McLaughlin and Shur (1987). Caput tissue was punctured with a 25-gauge needle and spermatozoa were allowed to 
disperse. Spermatozoa from both regions were filtered through Kimwipes and diluted to $2 \times 10^{6} \mathrm{ml}^{-1}$ before use. Capacitation and incubations were carried out for $1 \mathrm{~h}$ at $37^{\circ} \mathrm{C}$ in a moist atmosphere of $5 \% \mathrm{CO}_{2}$ in air. In some cases, $1 \mathrm{ml}$ samples of spermatozoa were centrifuged three times at $2000 \mathrm{~g}$ for $2 \mathrm{~min}$ each. The supernatants were removed and $1 \mathrm{ml}$ of fresh M199-M was added to the pellet to wash the cells. Before the next washing, the cells were resuspended by gentle agitation. The unwashed samples were centrifuged and resuspended in their original supernatants. Washes from $2 \times 10^{6}$ caput spermatozoa were used to treat an equal number of cauda spermatozoa.

\section{Inhibitor isolation and anti-trypsin activity}

A proteinase inhibitor (SVI) was isolated from homogenized seminal vesicle tissues as described by Poirier and Jackson (1981). The procedure consisted of gel filtration (Sephadex G-75), affinity chromatography using bovine pancreatic trypsin inhibitor as the ligand and ion exchange chromatography (SP-Sephadex C-25). Once purified, the inhibitor solution was dialysed against phosphate-buffered saline and stored at $-20^{\circ} \mathrm{C}$ until used. Chromatography materials were obtained from Pharmacia LKB Biotechnology, Inc. (Piscataway, NJ).

Measures of inhibitory activity were determined against porcine pancreatic trypsin with $N$-benzoyl-DL-arginine- $p$ nitroanilide (BAPNA: Sigma) as the substrate in $\mathrm{Ca}^{2+}$-free triethanolamine hydrochloride (TRA: Sigma) buffer, pH 7.8, $0.2 \mathrm{~mol} \mathrm{l}^{-1}$ (Fritz et al., 1974). Each $3.0 \mathrm{ml}$ assay contained $6.0 \mu \mathrm{g}$ trypsin (Sigma), $0.77 \mathrm{mmol} \mathrm{BAPNA}^{-1}$, and various amounts of inhibitor. An inhibitor unit (IU) is defined as the amount of inhibitor that reduces the hydrolysis of the substrate by $1 \mu \mathrm{mol} \mathrm{min} \mathrm{m}^{-1}$.

\section{Zonae}

Zonae were isolated from ovarian oocytes as described by Boettger et al. (1989). Zonae were solubilized just before use by incubation at $70^{\circ} \mathrm{C}$ for $30 \mathrm{~min}$ (Cholewa-Stewart and Massaro, 1972). The concentration of zonae used is expressed as zonae equivalents $(\mathrm{ZE})$. One thousand zonae per $10^{6}$ spermatozoa $\mathrm{ml}^{-1}$ represents 1 zona equivalent.

\section{Antiserum}

Antiserum to the seminal vesicle inhibitor used to induce acrosome reactions and verify inhibitor localization was raised in rabbits; its specificity has been established by Poirier and Jackson (1981), Irwin et al. (1983), Richardson et al. (1987) and Aarons et al. (1991).

\section{Coomassie brilliant blue method for acrosome staining}

Spermatozoa were scored for acrosome integrity by the Coomassie brilliant blue staining technique (Moller et al., 1990) as modified by Aarons et al. (1991, 1992). Spermatozoa were fixed with equal amounts of $10 \%$ formaldehyde in phosphate-buffered saline (PBS) for $10 \mathrm{~min}$, washed once with PBS at $6500 \mathrm{~g}$ for $1 \mathrm{~min}$, and dried onto glass slides. The cells were stained for $2 \mathrm{~min}$ in $0.05 \%$ Coomassie brilliant blue R-250 (BioRad Laboratories, Richmond, CA). The slides were rinsed with PBS and the spermatozoa covered with PBS: glycerol ( $1: 1$ by volume) and observed. Previous investigations (Aarons ef al., 1991) indicate that the Coomassie brilliant blue staining method, which stains the acrosomal cap, is as sensitive as the chlortetracycline assay (Leyton and Saling, 1989) in determining acrosome integrity after ionophore (A23187) or zonae treatment.

\section{Induction of acrosome reaction}

Spermatozoa were induced to acrosome react by immunoaggregation of bound SVI as described by Aarons et al. (1991). Cells $\left(2 \times 10^{6} \mathrm{ml}^{-1}\right)$ were suspended in M199-M and incubated for $1 \mathrm{~h}$ to induce capacitation. Purified preparations of SVI in PBS were added to give a final inhibitor concentration of $30 \mathrm{mIU} 10^{-6}$ sperm cells. After incubation for $30 \mathrm{~min}$ at room temperature, the sperm cells were then washed twice at $2000 \mathrm{~g}$ for $2 \mathrm{~min}$ in M199-M. Samples of the inhibitor-treated cells were incubated for an additional $30 \mathrm{~min}$ in a 1:40 dilution of anti-SVI serum. Controls consisted of substituting normal rabbit serum or PBS for the immune serum. These samples were then fixed and stained with Coomassie brilliant blue. Two zonae equivalent are sufficient to induce acrosome reactions in most incubated cauda spermatozoa (Boettger-Tong et al., 1992). In the controls fucoidan or PBS were substituted for the zonae.

\section{Indirect immunofluorescence}

The details of the indirect immunofluorescent technique used to detect the presence of seminal inhibitor on spermatozoa were described by Aarons et al. (1991, 1992) and BoettgerTong et al. (1992). Controls consisted of substituting PBS for SVI or substituting normal rabbit serum or PBS for the immune serum.

\section{Statistical analysis}

Contingency table analyses were used to test for significance of differences between proportions (Sokal and Rohlf, 1981). The level of significance was defined as $P$ values $<0.05$. Differences were not significant if not indicated.

\section{Results}

Unwashed caput spermatozoa, incubated under capacitating conditions, did not acrosome react when presented with solubilized zonae (Fig. 1). However, if the capacitated samples were washed before the addition of the zonae, a significant decrease in the percentage of spermatozoa with intact acrosomes was seen. If fucoidan or PBS was substituted for zonae, no significant decrease was observed. Unwashed cauda spermatozoa responded to zonae, and washing also increased the percentage of these cells that reacted. No differences were observed between the washed and unwashed controls (PBS) for either caput or cauda spermatozoa, suggesting that the 


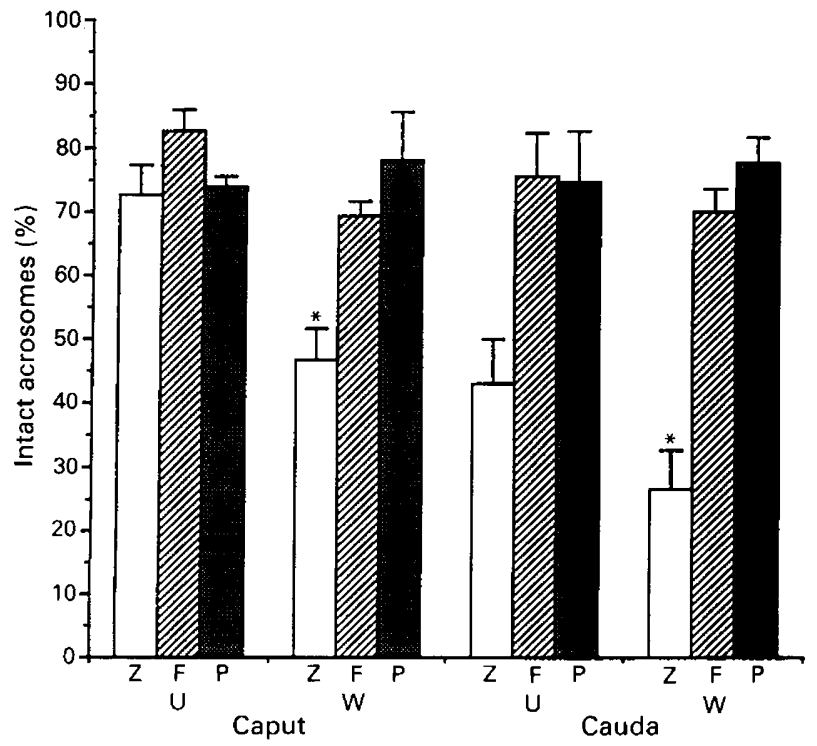

Fig. 1. Caput and cauda spermatozoa were incubated under capacitating conditions then washed $(W)$ or left unwashed (U), and induced to acrosome react with heat solubilized zonae $(\mathrm{Z})$, fucoidan $(\mathrm{F})$ or phosphate-buffered saline (PBS) (P). Fucoidan was used at a final concentration of $5 \mathrm{mg} \mathrm{ml}^{-1}$ and zonae at two zonae equivalents. The data represent the percentages of spermatozoa with intact acrosomes as determined by Coomassie blue staining and are the means of three separate trials counting 200 cells per treatment per trial. The horizontal lines represent the standard errors of the means. *Significantly different from the unwashed sample $(P<0.05)$.

procedures used were not detrimental to acrosome integrity. Similar results were obtained when the acrosome reactions were induced by immunoaggregation of a zona binding site (Fig. 2). Capacitated, unwashed caput cells did not acrosome react, while capacitated, unwashed cauda spermatozoa did react to SVI/anti-SVI treatment. Washing increased the ability of both caput and cauda spermatozoa to react to immunoaggregation. No motility was observed in the incubated caput spermatozoa after the washes.

The cells were treated with pertussis toxin and then induced to acrosome react to determine whether the acrosomes of caput and cauda spermatozoa react by similar mechanisms. Pertussis toxin blocked immunoaggregated acrosome reactions in both caput and cauda spermatozoa (Fig. 3). The effect was more dramatic with cauda spermatozoa.

As washing is necessary for incubated caput spermatozoa to acrosome react to zona or to an immunoaggregation stimulus, we determined whether washing alone, with no capacitationincubation, could accomplish the same effect. Fresh caput and cauda spermatozoa were washed three times and tested for ability to acrosome react by immunoaggregation after each washing (Fig. 4). Washing alone did not prepare either caput or cauda spermatozoa for immunoaggregation-induced acrosome reactions.

Indirect immunofluorescence was used to determine when during the washings SVI could bind to the caput cells. SVI binds to the acrosomal cap region of both caput and cauda spermatozoa, albeit in much lower percentages for the caput cells (Irwin et al., 1983). With successive washings the percentage of caput spermatozoa that bind SVI increased to equal that

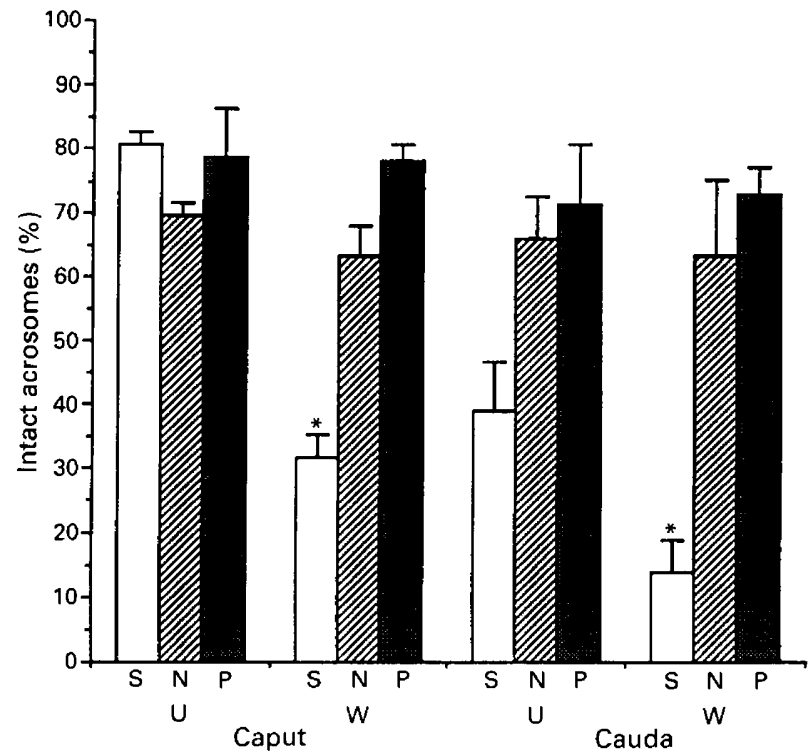

Fig. 2. Caput and cauda spermatozoa were incubated under capacitating conditions then washed $(W)$ or left unwashed $(U)$ and induced to acrosome react with SVI anti-SVI treatment (S), SVI-normal rabbit serum $(\mathrm{N})$ or phosphate-buffered saline (PBS)-PBS (P). The data represent the percentages of spermatozoa with intact acrosomes as determined by Coomassie blue staining and are the means of three separate trials counting 200 cells per treatment per trial. The horizontal lines represent the standard errors of the means. *Significantly different from the unwashed sample $(P<0.05)$.

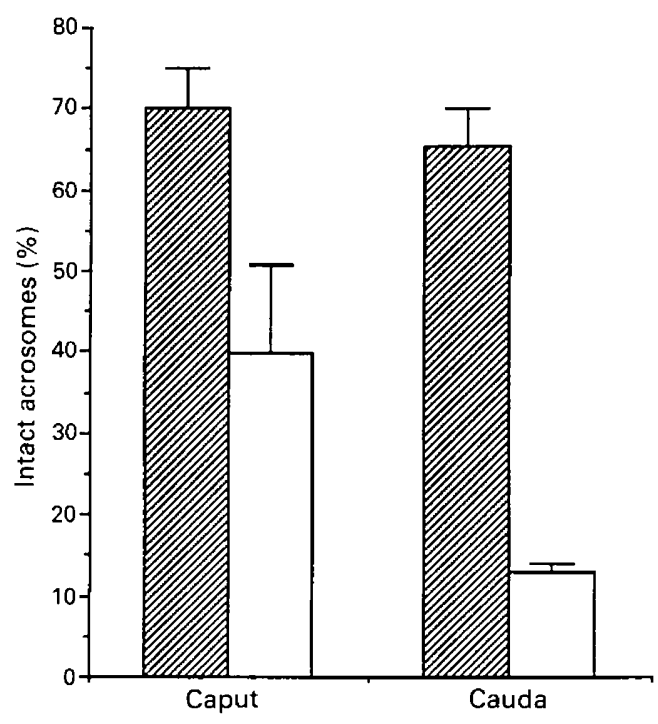

Fig. 3. Capacitated caput and cauda spermatozoa were washed and induced to acrosome react by SVI anti-SVI in the presence (四) or absence $(\square)$ of pertussis toxin (10 $\mu \mathrm{g} \mathrm{ml}^{-1}$ ). The data represent the percentages of spermatozoa with intact acrosomes as determined by Coomassie blue staining and are the means of three separate trials counting 200 cells per treatment per trial. The horizontal lines represent the standard errors of the means.

obtained for cauda cells (Fig. 5). No fluorescence was seen under any of the control situations. Spermatozoa were induced to acrosome react after each wash to determine when during 


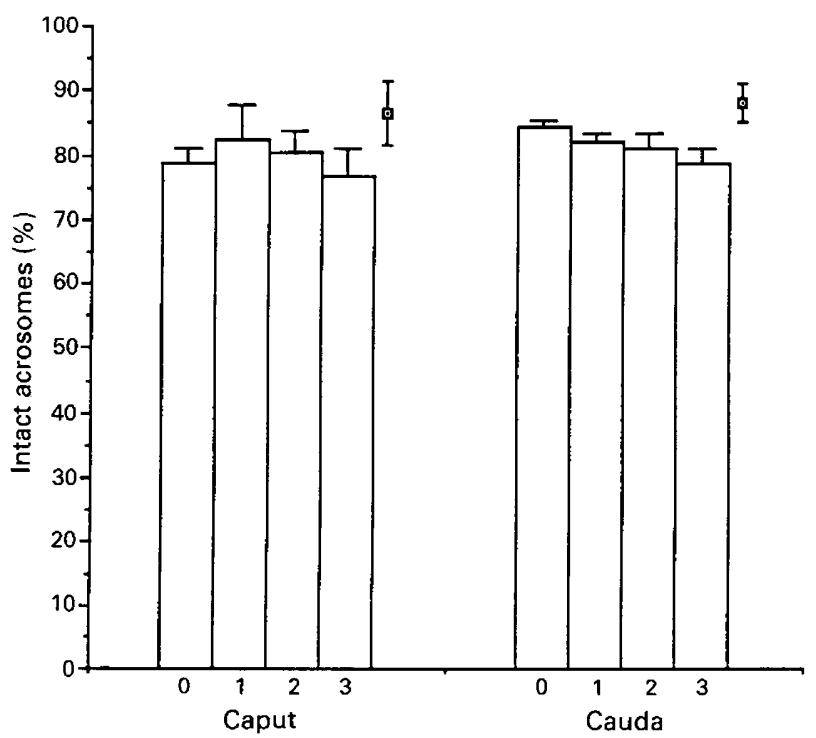

Fig. 4. Unincubated caput and cauda spermatozoa were induced to acrosome react by SVI anti-SVI treatment when unwashed (0) or after each of three $(1,2,3)$ successive washes. The data represent the percentages of spermatozoa with intact acrosomes as determined by Coomassie blue staining and are the means of three separate trials counting 200 cells per wash per trial. The horizontal lines represent the standard errors of the means. The data points at the top of the bars represents control data with PBS substituted for SVI.

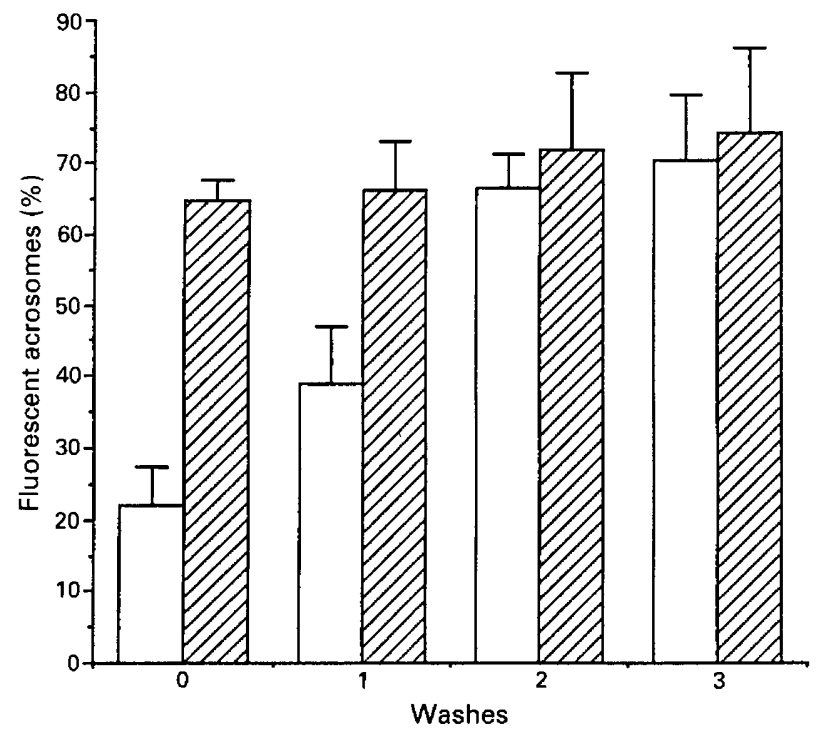

Fig. 5. Caput ( $\square$ ) or cauda (四) spermatozoa incubated under capacitating conditions were tested for their ability to bind SVI as determined by indirect immunofluorescence when left unwashed $(0)$ or after each of three $(1,2,3)$ successive washes. The data represent the percentages of spermatozoa that bind SVI at the acrosomal cap region and are the means of three separate trials counting 200 cells per treatment per trial. The horizontal lines represent the standard errors of the means.

the washing procedure capacitated caput spermatozoa could react to immunoaggregation (Fig. 6). A progressive decrease in the percentage of intact acrosomes was observed for both the

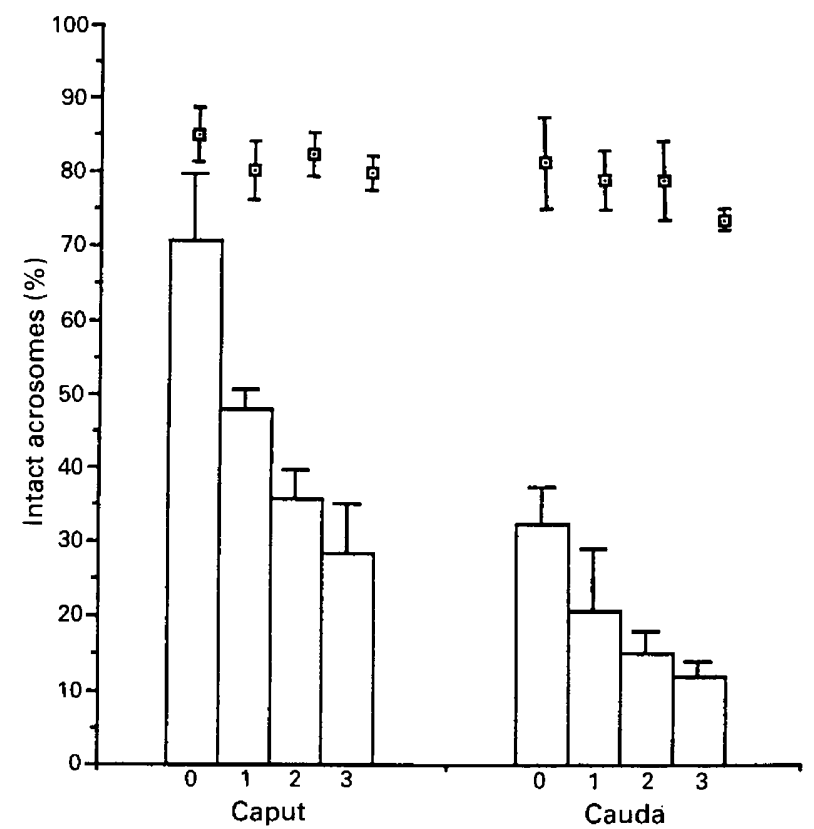

Fig. 6. Caput or cauda spermatozoa incubated under capacitating conditions were induced to acrosome react by SVI anti-SVI treatment when unwashed $(0)$ or after each of three $(1,2,3)$ successive washes. The data represent the percentages of spermatozoa with intact acrosomes as determined by Coomassie blue staining and are the means of three separate trials counting 200 cells per treatment per trial. The horizontal lines represent the standard errors of the means. The data points at the top of each clear bar represent control data with PBS substituted for SVI.

caput and cauda cells. No significant decrease in control (PBS or normal rabbit serum treated) samples was observed.

As washing effectively increased the percentage of caput spermatozoa that could bind SVI and react to immunoaggregation, the ability of the caput washes to block acrosome reaction induction in cauda spermatozoa was determined. Incubated, washed cauda spermatozoa were mixed with supernatants removed from incubated caput spermatozoa samples and induced to acrosome react by immunoaggregation. These supernatants effectively reduced the number of incubated, washed cauda cells that acrosome reacted (Fig. 7). The supernatants, however, did not completely block SVI/anti-SVI induced acrosome reactions.

The washes contained trypsin inhibitory activity (Table 1 ) as determined by the BAPNA assay. The amount of inhibitory activity in the supernatants was reduced with each wash for both the caput and cauda cells. No differences were seen in the amount of trypsin activity when caput and cauda supernatants were compared.

\section{Discussion}

Capacitation has been defined as the biochemical modifications that spermatozoa undergo before they can be induced to acrosome react (Zaneveld et al., 1991) in response to a zona agonist (Florman and Babcock, 1991). The ability to acrosome react in response to zonae, the physiological acrosome reaction, is considered a distinguishing characteristic of the fertile state 


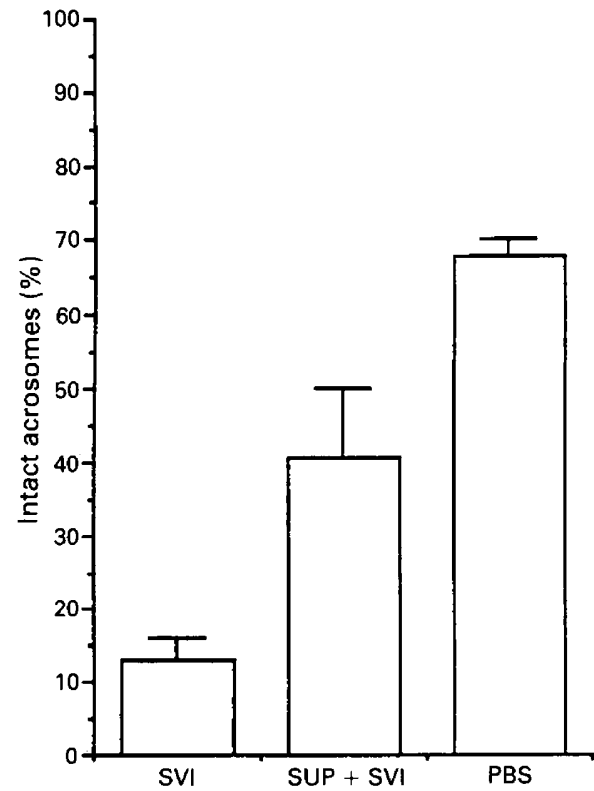

Fig. 7. Incubated washed cauda spermatozoa were treated with supernatants obtained from washing incubated caput spermatozoa. Supernatants $(1 \mathrm{ml})$ obtained from the first wash of $2 \times 10^{6}$ caput spermatozoa were used to treat $2 \times 10^{6}$ cauda spermatozoa. The cauda cells were treated with either SVI, supernatant (SUP) plus SVI or PBS and then induced to acrosome react with anti-SVI. The data represent the percentages of spermatozoa with intact acrosomes. as determined by Coomassie blue staining and are the means of six separate trials counting 200 cells per treatment per trial. The horizontal lines represent the standard errors of the means.

Table 1. Trypsin-inhibitor activity of supernatants removed during three successive washes of mouse epididymal spermatozoa

Epididymal region Wash Inhibitor activity $\left(\mathrm{mIU} \mathrm{ml}{ }^{-1}\right)^{\mathrm{ab}}$

$\begin{array}{crr}\text { Caput } & 1 & 15.2 \pm 8.4 \\ & 2 & 9.0 \pm 4.5 \\ \text { Cauda } & 3 & 6.8 \pm 1.5 \\ & 1 & 14.2 \pm 10.9 \\ & 2 & 7.4 \pm 3.0 \\ & 3 & 6.7 \pm 1.2\end{array}$

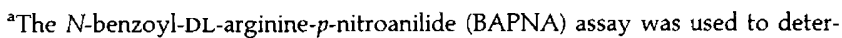
mine the trypsin-inhibitor activity of the supernatant from each washing, based on removal of $1 \mathrm{ml}$ washes from $2 \times 10^{\circ}$ cells; b the data represent the means and SEM from three separate investigations.

(Florman and Babcock, 1991). Thus the incubated, washed caput spermatozoa, as used in experiments presented here, are capacitated. As the incubations and washing did not increase the motility of the caput cells, it is difficult to consider them fertile. Fucoidan, a sulfated L-fucose polymer with antitrypsin activity was used as a negative control for the zonae based experiments. Although fucoidan can block sperm-zona binding in a number of species (Töpfer-Peterson and Henschen, 1988), it cannot induce acrosome reactions in either caput or cauda cells. Capacitated unwashed caput spermatozoa will acrosome react when treated with an ionophore, a non-physiological stimulus (Lakoski et al., 1988). This finding suggests that the inability of these cells to react to zonae is due to a block somewhere proximal to the $\mathrm{Ca}^{2+}$ influx step. Washing appears to remove the block but only from cells incubated under capacitating conditions. The fact that pertussis toxin effectively blocks SVI/anti-SVI induced reaction in both caput and cauda cells suggests that a $G$ protein is involved in the exocytosis in both groups of cells. Pertussis toxin also blocks zonae induced acrosome reactions of cauda spermatozoa (Endo et al., 1987). The fact that caput and cauda spermatozoa react to the same stimuli by similar mechanisms suggests that caput acrosome reactions are true reactions. Pertussis toxin has no effect on the ability of mouse spermatozoa to bind SVI (Boettger-Tong et al., 1992).

Unwashed capacitated cauda spermatozoa can acrosome react, but washing is necessary for induction of the acrosome reaction in capacitated caput spermatozoa. The ability to induce acrosome reactions in caput cells may be a function of dilution rather than washing. The caput region of the epididymis has only $2-5 \%$ of the spermatozoa found in the cauda region (McLaughlin and Shur, 1987). To achieve equal concentrations, as used in the assays presented here, the cauda cells were diluted much more than were the caput cells. Thus components removed from caput spermatozoa by washing may be removed from cauda spermatozoa by dilution.

It has been proposed that physiological acrosome reactions could be induced without zonae by immunoaggregation of zonae binding sites (Saling, 1989). Mouse cauda spermatozoa, incubated under capacitating conditions, will acrosome react when stimulated by zonae (Bleil and Wassarman, 1983) or by immunoaggregation of zonae binding sites (Aarons et al., 1991, 1992; Leyton and Saling, 1991; Macek et al., 1991). Acrosome reactions induced in cauda cells by solubilized zonae and SVI/anti-SVI are similar in a number of respects; both are sensitive to pertussis toxin and proteinase inhibitors and are inducible by nanomolar quantities (Boettger-Tong et al., 1992). In addition, incubated washed caput spermatozoa will effectively react to both stimuli.

Washing removes a component(s) that allows caput spermatozoa to bind to whole zonae (McLaughlin and Shur, 1987), as well as allowing them to bind SVI and undergo physiologically induced acrosome reactions. Components in the washings removed from caput cells will block zonae binding (McLaughlin and Shur, 1989) as well as SVI/anti-SVI induced acrosome reactions. Thus, inherent proteinase inhibitors may be at least partially responsible for the inability of the caput cells to react. Mouse epididymides contain at least two proteinase inhibitors that are distinct from that of the seminal vesicle (Poirier and Jackson, 1981). Thus, it is not surprising that the washes should contain anti-trypsin activity. However, since caput and cauda washes contain approximately the same amount of trypsin inhibitory activity, the blocking ability of the cauda supernatant is not due to total inhibitory activity; but may be due to the type of inhibitor or component present or to components without anti-trypsin activity that only secondarily block SVI binding sites.

It has been suggested that epididymal spermatozoa are covered with decapacitation factors that protect zona binding 
sites and inhibit sperm motility (Bleil, 1991). Some of these components may limit membrane fluidity, thus preventing spermatozoa from undergoing premature acrosome reactions. Epididymal components that block zonae binding (McLaughlin and Shur, 1987) or stabilize the acrosome (Thomas et al., 1984) are known. These and similar observations along with the data presented here support the suggestion of negative regulation: caput or even testicular spermatozoa have some features necessary for successful fertilization, for example functional zona binding sites and mature second message systems that are masked by negative regulators (Florman and Babcock, 1991). Epididymal maturation may then be thought of, at least in part, as an increase in the efficiency of regulator removal. The data suggest that incubation under capacitating conditions can induce changes in the plasma membrane of caput cells that are similar to those induced in cauda spermatozoa. However, physiological acrosome reactions cannot be induced in these cells because the zona binding sites are blocked by negative regulators. The regulators normally removed during epididymal transit can be removed from capacitated caput spermatozoa by washing. Washing also has a small effect on the ability of the cauda cells to react, suggesting that not all the regulator is removed during the epididymal transit.

The authors are grateful to A. M. Cusic for advice and constructive criticism of the work and to C. Bunn and F. Oglesby for excellent secretarial assistance.

\section{References}

Aarons D, Boettger-Tong H, Holt G and Poirier GR (1991) Acrosome reaction induced by immunoaggregation of a proteinase inhibitor bound to the murine sperm head Molecular Reproduction and Development 30 258-264

Aarons D, Battle T, Boettger-Tong H and Poirier GR (1992) Role of monoclonal antibody J-23 in inducing acrosome reactions in capacitated mouse spermatozoa Journal of Reproduction and Fertility 96 49-59

Bleil JD (1991) Sperm receptors of mammalian eggs Elements of Mammalian Fertilization pp 133-151 Ed. PM Wassarman. CRC Press, Boca Raton

Bleil JD and Wassarman PM (1983) Sperm-egg interaction: sequence of events and induction of the acrosome reaction by a zona pellucida glycoprotein Developmental Biology 95 317-324

Boettger-Tong H, Richardson R, Free D, Rushing S and Poirier GR (1989) Effects of in vitro incubation on a zona binding site found on murine spermatozoa Journal of Experimental Zoology 249 90-98

Boettger-Tong H, Aarons D, Biegler B, Lee T and Poirier GR (1992) Competition between zonae pellucida and a proteinase inhibitor for sperm binding Biology of Reproduction 47 716-722

Cholewa-Stewart J and Massaro EJ (1972) Thermally induced dissolution of the murine zona pellucida Joumal of Andrology 3 373-381

Endo Y, Lee MA and Kopf GS (1987) Evidence for a role of a guanine nucleotide-binding regulatory protein in the zona pellucida-induced mouse sperm acrosome reaction Developmental Biology 119 210-216

Florman HM and Babcock DF (1991) Progress toward understanding the molecular basis of capacitation Elements of Mammalian Fertilization pp 105-132 Ed. PM Wassarman. CRC Press, Boca Raton
Fritz H, Traultschold I and Werle E (1974) Proteinase inhibitors Methods of Enzymatic Analysis pp 1064-1080 Ed. HU Bergmeyer. Academic Press, New York

Irwin M, Nicholson N, Haywood T and Poirier GR (1983) Immunofluorescent localization of murine seminal vesicle proteinase inhibitor Biology of Reproduction 28 1021-1026

Lakoski KA, Carron CP, Cabot CL and Saling PM (1988) Epididymal maturation and the acrosome reaction in mouse sperm: response to zona pellucida develops coincident with modification of M42 antigen Biology of Reproduction 38 221-233

Leyton L and Saling PM (1989) Evidence that aggregation of mouse sperm receptors by ZP3 triggers the acrosomal reaction Journal of Cell Biology 108 2163-2168

Leyton L and Saling PM (1991) A monoclonal antibody against p95, a receptor for $\mathrm{ZP} 3$, induces the acrosome reaction in mouse sperm. In Program of the 31st Annual Meeting of the American Society for Cell Biology, Boston, MA. Abstract 2681

Macek MB, Lopez LC and Shur BD (1991) Aggregation of B-1,4galactosyltransferase on mouse sperm induces the acrosome reaction Developmental Biology 147 440-444

McLaughlin JD and Shur BD (1987) Binding of caput epididymal mouse sperm to the zona pellucida Developmental Biology 123 557-561

Moller CC, Bleil JD, Kinloch RA and Wassarman PM (1990) Structure and functional relationships between mouse and hamster zona pellucida glycoproteins Developmental Biology 137 276-286

Orgebin-Crist MC (1987) Post-testicular development of mammalian spermatozoa Morphological Basis of Human Reproduction Function pp 155-174 Eds C Spera and DM deKretser. Plenum Press, New York

Pavlok A (1974) Development of the penetration activity of mouse epididymal spermatozoa in vivo and in vitro Joumal of Reproduction and Fertility 36 203-205

Peterson RN, Hunt WP and Henry LH (1986) Interaction of boar spermatozoa with porcine oocytes: increase in proteins with high affinity for the zona pellucida during epididymal transit Gamete Research 14 57-64

Poirier GR and Jackson J (1981) Isolation and characterization of two proteinase inhibitors from the male reproductive tract of mice Gamete Research 4 555-569

Richardson R, Buckingham T, Boettger $\mathbf{H}$ and Poirier GR (1987) A monoclonal antibody to a zona pellucida-proteinase inhibitor binding component on murine spermatozoa Journal of Reproductive Immunology 11 101-116

Saling PM (1982) Development of the ability to bind to zonae pellucidae during epididymal maturation: reversible immobilization of mouse spermatozoa by lanthanum Biology of Reproduction 26 429-436

Saling PM (1989) Mammalian sperm interaction with extracellular matrices of the egg Oxford Reviews of Reproductive Biology 11 339-388

Sokal RR and Rohlf FJ (1981) Biometry (2nd Edn). W H Freeman and Co., San Francisco

Thomas TS, Reynolds AB and Oliphant G (1984) Evaluation of the site of synthesis of rabbit sperm acrosome stabilizing factor using immunocytotechnical and metabolic techniques Biology of Reproduction 30 693-705

Töpfer-Peterson E and Henschen A (1988) Zona pellucida-binding and fucosebinding of boar sperm acrosin is not correlated with proteolytic activity Biological Chemistry Hoppe-Seyler 369 69-76

Yanagimachi R (1981) Mechanisms of fertilization in mammals Fertilization and Embryonic Development In Vitro pp 81-182 Eds L Mastroianni and JD Biggers. Plenum Press, New York

Yanagimachi R (1988) Mammalian fertilization. In The Physiology of Reproduction pp 135-185 Eds E Knobil and J Neill. Raven Press, New York

Zaneveld LJD, DeJonge CJ, Anderson RA and Mack SR (1991) Human sperm capacitation and the acrosome reaction Human Reproduction 6 $1265-1274$ 